\title{
THE STUDY OF THE EFFECT OF POLYMER-ADENOSINE MOLECULAR COMPLEXES ON THE THERMAL BURN MODEL
}

\author{
A.A. Ermolaeva ${ }^{2}$, V.V. Ponomarenko ${ }^{2}$, A.V. Novoselov', \\ E.D. Semivelichenko², D.Yu. Ivkin'², A.V. Eremin' \\ ${ }^{1}$ IMC RAS, 31 Bolshoy Ave., V. O., Saint Petersburg, \\ 190004, Russia ${ }^{2}$ Saint-Petersburg State Chemical-Pharmaceutical University, \\ Professor Popov st.14, Saint Petersburg, Russia, 197376.
}

DOI: 10.19163/MedChemRussia2021-2021-537

E-mails: ha9room@gmail.com, veronika.ponomarenko@spcpu.ru

In modern pharmacology, biocompatible polymers are widely used as components of drugs, while cases when they are directly the active principle of a drug are quite rare. As a rule, the role of biocompatible polymers is limited to the field of excipients, the base of the buffer system of drug solutions, stabilization of the dosage form as part of a pharmaceutical substance or in solution.

Molecular complexes of biocompatible polymers based on weak, nonvalent polymer-substance interactions can act as prolongers of drug action, modifiers of drug administration into the body, and, in particular, allow the creation of drugs based on adenosine (Ad), an effective anti-inflammatory agent, which modulates many physiological processes acting on receptors associated with G-protein and significantly accelerates tissue healing [1]. Series of drugs were identified as part of this study of the thermal burn model. A series of preparations - molecular complexes based on a copolymer (VP-KK, VM:KK = 9:1, MM $12500 \mathrm{Da}$ ) N-vinylpyrrolidone (VP) with crotonic acid (CA) with adenosine and containing alainate complexes $\mathrm{Cu}(\mathrm{II})$ or $\mathrm{Zn}-\mathrm{M}(\mathrm{ala})_{2}$ in comparison with the reference drug «Depanto ${ }^{\circledR}{ }$.

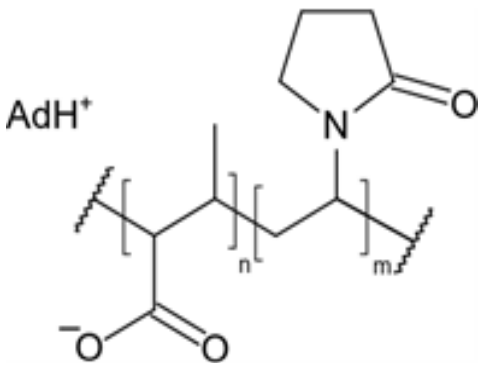

The preparations copolymer-Ad $(90: 10$ mol\%) and copolymer-Ad-Cu"(ala) (90:9:1\% mol.) showed results comparable or superior to the comparison drug. A good moisturizing effect of the drugs on the burn area was noted, however, the effectiveness of the drug was reduced due to the development of secondary infections in the wound area. In further studies, a modification is planned to level this factor.

\section{Reference}

[1]. Feoktistov I., Biagioni I., and Bracket B. N. (2009) Adenosine receptors in wound healing, fibrosis, and angiogenesis. In: Wilson C., Mustafa S. (eds) Adenosine receptors in health and disease. Handbook of Experimental Pharmacology, volume 193. Springer, Berlin, Heidelberg. https://doi.org/10.1007/978-3-540-89615-9_13. 